\title{
Phoneme Distribution and the Sonority Nature of Consonant Clusters in Afaan Oromo
}

\section{Tariku Negese Oncho}

Ph.D.

\author{
Assistant Professor of Linguistics \\ Wollega University \\ Oromia, Ethiopia \\ taserese@gmail.com
}

\begin{abstract}
This paper examines an outline of two main phonological elements in the Oromo language. Firstly, it indicates the permissible sequences and types of the language's consonant clusters given the member sound's sonority. Secondly, it enlightens the distribution of Oromo phonemes in different word positions (initial, medial, and final). In this aspect, the study is a descriptive work and attention has been given mainly to recounting the simple distribution rather than theorizing the phonotactic processes. For the study, data was collected from five native speakers of the Western dialect and was phonemically transcribed using an IPA symbol. The speech of these participants has three hours of duration with an average speech length of 36 minutes for each participant. The study also attempts to list out the number of the language's native and loan phonemes employed in the speech of adult Oromo users comparing the data with the earlier studies. With the study, it was observed that Oromo has Sonorant-Obstruent, Obstruent-Obstruent, Obstruent- Sonorant and Sonorant - Sonorant
\end{abstract}


clusters based on the status of sonorants in its phonological system. Of the two-member clusters in clustering, sonorants are the dominant first member sounds in the language.

Keywords: Consonant Cluster, Distribution, Obstruent, Sonorant, Sonority

\section{Introduction}

Languages do not allow random sequences of sounds (Fasold \& Connor-Linton, 2006) and have a distinct pattern of arrangement. That means the sound sequences a language permits in its structure are systematic and predictable. For instance, two or more languages with similar, even identical phoneme inventories (if available) may at least have very diverse rules governing the distribution in morphemes, words, and syllables. Cognizant of this, an attempt was made to provide the phonotactic constraints relying with the consonant clusters of Oromo with reference to sonority of the consonants.

Sonority is the relative perceptual prominence of one sound class against another (Syrika, Nicolaidis, Edwards, \& Beckman, 2011) which is "best defined in terms of a linear regression equation derived from the observed intensity results" (Parker, 2002). Consonants are ranked on such a sonority scale. In consonants the sonority index declines from liquids (in fact from glides) over nasals to obstruents (Rauch, 2003). Sonority difference or distance between the cluster members converts into their relative markedness (Yavas, 2013). A version of a sonority scale from most sonorous to least sonorous, drawn from Juliette (1995) is provided below (where the numbers represent the sonority index and ' $>$ ' means 'is greater in sonority than').

Sonority scale (Juliette, 1995) 
vowels $>$ glides $>$ liquids $>$ nasals $>$ fricatives $>$ stops

$\begin{array}{llllll}6 & 5 & 4 & 3 & 2 & 1\end{array}$

High sonority <----------------------------------> Low sonority

The purpose of this paper, therefore, is to consider the sonority differences between the members of Oromo consonant clusters as per the hypothesis of sonority for which few evidences exist.

\section{Methodology and Data Sources}

For this study, both primary and secondary sources are consulted. The primary one was introspection since I am a native speaker of the western (Wallaga) variety of Oromo. Additional data were collected from five native speakers of the language using an interview. The dialect of the data sources was the second cluster variety or the Mecha dialect as per the former categorization. The interview topics were familiar to the informants and each of the informants responded to the questions for about 36 minutes on average. The responses of the participants were recorded using Digital Audio Tape (DAT). The secondary sources referred include studies done on Oromo particularly on the dialect under inquiry. This is done to confirm the validity of some of the conclusions cited as background information. The framework used is the structural framework. This is because, since there is a lack of exhaustive descriptive work on the phonology of Oromo, I believe that theorizing should only come after the availability of sufficient descriptive works.

3. The language and its sounds

Oromo is one of the most widely spoken languages in Africa (Abraham, Huang, \& Liu, 2014) with huge number of native speakers (Dejene, 2019) inhabiting chiefly within 
Oromia ${ }^{1}$ regional state. It is classified genetically as East lowland Cushitic in the Afro-Asiatic super family (phylum). From the Cushitic speakers more than two-thirds are Oromo (Mekuria, 1995). In fact, in almost every part of the regional states of the country (if not all), it is likely to find an Oromo speaking people forming a diverse dialect. Oromos describe their language as 'Afan Oromo' (literally mouth of Oromo) even if the present study used the term Oromo referring to both.

The language is spoken in a choice of dialects and was organized into different categories based on special scenarios. Previously, Kebede (2005) and Gragg (1976) listed five dialects considering users' geographical sites. Lately, Feda (2015) systematized Oromo varieties by indicating hierarchies of small and big clusters. He, thus, classified the dialects into three big clusters where the first cluster comprises varieties such as Arsi-Bale, Harar, Wollo-Rayya. The second and third include Wollega-Ilubabor-Jimma, Shawa and BoranaGuji, respectively.

Oromo constitutes its own consonant and vowel phonemes that earlier phonological works consistently described. In the previous phonological studies of Oromo 24 native consonants and sounds like /p, v, z, s'/ in loan words were listed along with five vowel sounds (Fikadu, 2014). Similarly, consistent with these former studies, this study listed the consonant and vowel sounds employed in the speech of the participants.

Majority of the consonant sounds are obstruents. In addition to the consonants, five vowel sounds were distinguished with their long counterparts. Lip rounding and relative tongue position are the defining characteristics of the vowels. In view of the parameter of lip rounding, all the vowels except the two back vowels are unrounded. In the mouth, the position of the tongue determines the shape of the oral cavity, which divides the vowels into

\footnotetext{
${ }^{1}$ It can be spelt otherwise as Oromiya, which is believed to be a simplified combination of the words Oromo (the people) and biyya (land) (Mekuria, 1995). As stated by Mekuria (1995) Oromos often refer to a country as the land of so and such people.
} 
three great classes: (a) front vowels, (b) back vowels, and (c) central vowels. Appendix (B) show is a chart that shows Oromo vowel sounds/phonemes identified in the speech of the participants. Different vowels never coalesce to make a diphthong, but similar vowels may combine to bring about a contrastive vowel length in an identical environment for all consonants of the language.

4 Results

Languages that permit the realization of consonant clusters (CCs) generally restrict the possible combinations of the consonants in a cluster. Some of the restrictions are universal and others are language-specific. Oromo generally permits two kinds of CCs depending on the participating members. The first is C-lengthening where an identical consonant coalesce forming a geminate consonant $(\mathrm{CxCx})$. All the Oromo consonantal sounds except the glottals can appear in this form creating a geminate sound. The other form of word medial CCs originates from a dissimilar sounds' coalesces $(\mathrm{CxCy})$. In this case, the /n,r,l/ are the most widespread Cxs (first members) while /d,P,ç, // in no way happen as Cxs. It would seem that $/ 1 /$ and $/ \mathrm{r} /$ are the sounds recurrently taking place with different sounds Cxs followed by $/ \mathrm{n} /$; they normally happen with no less than $50 \%$ of the remaining consonants of the language. Furthermore, $/ \mathrm{t}, \mathrm{d}, \mathrm{c}, \mathrm{j}, \mathrm{P}, \mathrm{t}, \mathrm{d}, \mathrm{h}, \int, \mathrm{w}, \mathrm{j} / \mathrm{do}$ not occur in the position of $\mathrm{Cx}$ in a cluster while /n,h, $, \mathrm{w}, \mathrm{j} /$ don't make the Cy (Habte, 2003).

Yet, there are some constraints on the consonants while occurring in word medial position as clusters. Depending on their occurrence restrictions, Wako (1981) grouped consonants of the language occurring in a cluster into four. These are consonants making $(\mathrm{Cx}),(\mathrm{Cy})$, both $\mathrm{Cy}$ and $\mathrm{Cx}$, and finally, consonants never occurring as a cluster. With this classification, the majority of the phoneme sounds characterized under each of the groupings are acceptable although a few phonemes are miscategorised. For example /w, h/ are consonants sorted as phonemes never occurring as clusters; but it is difficult to generalize 
since some morphological processes may ensue co-occurrences as in the case of [Pofwalla:lu:] 'fainting'. Additionally, /n/ was speciously regarded as a phoneme that "[does] not combine with any other consonant phonemes as [a] second [member] to form a cluster." In the language, words like /fač'a:sne/ 'we sowed', /k'abna/ 'we have', and /humna/ 'power' are some of the words I encountered with the sound in a cluster as Cy.

In essence, the language has only some types of consonants to occur in a cluster. With this review, only nine sounds checked out of the entire consonantal phonemes can make the $\mathrm{Cx}$ in a cluster although the number of the second members (Cy) may exceed the listed sounds. See details of the occurrences of the language's sounds while making a cluster categorizing the sounds depending on their manner feature. It is also better to note that the tables contain non-exhaustive list owing to some morphological processes in the language; again other missing expressions may exist in the language other than the ones listed for this study from the collected data. The morphological processes happen when a morpheme ending with a consonant is attached or prefixed to a word/morpheme or a suffix morpheme beginning with a consonant is attached to a word/morpheme ending with a consonant.

A rough sonority scale is used throughout this paper, with broad categories of segments to make the analysis as widely applicable as possible. However, a more involved analysis would essentially discover this issue. Initially, some Oromo CCs are comprised of Cx stops and some other consonants as shown in (2).

$\begin{array}{ll}\text { Instance Recorded } & \text { Gloss } \\ \text { /Pabju:/ } & \text { 'dream' } \\ \text { /Pibsa:/2 } & \text { 'light' } \\ \text { /Pabfa:la/ } & \text { 'astute' }\end{array}$

\footnotetext{
${ }^{2}$ It can sometimes be realized phonetically as [?ifsa:] where voiceless fricatives make a cluster.
} 


$$
\begin{array}{ll}
\text { / doksa:/ } & \text { 'secret' } \\
\text { /dugda/ } & \text { 'back' } \\
\mathrm{C}_{2} \text { s of } \mathrm{C}_{1} \text { stops in Oromo }
\end{array}
$$

Oromo sets up CCs only with three of its six stop sounds (/b, k, g/) as first member. Clusters made with bilabial and velar stops indicated as a first member take an affricate [j] and fricatives with alveolar and palatal places of articulation. The other sound making the second member is the alveolar voiced stop, which is often realized phonetically as an alveolar sound as a result of assimilation (this is a case whereby a sound will change to become more like an adjacent sound). The sonority scales of the sounds seem to be very small; because the range between sonority scale given to fricatives and stops are two and one, respectively. Pertaining to the affricate sound, it was commonly assigned a lower sonority index even if scholars differ on the value assigned to the sound class. Yet, the majority of them like for example (Katamba, 1989) agree that affricates should be placed between fricatives and stops with a descending sonority index (fricatives > affricates > stops). In all these cases, the sounds were composed of obstruents which were given the lowest sonority scale.

In the language the most widely used first members are liquids (i.e. lateral and trill). Example (3) and (4) indicate instances recorded for the lateral and trill first member followed by different consonants, respectively.

(3)

$\begin{array}{llll}\text { Instance Recorded } & \text { Gloss } & \text { Instance Recorded } & \text { Gloss } \\ \text { /balPina/ } & \text { 'width' } & \text { /silga/ } & \text { 'colostrum' } \\ \text { /jalde:ssa/ } & \text { 'monkey' } & \text { /silmi:/ } & \text { 'tick' } \\ \text { /jilba/ } & \text { 'knee' } & \text { /walsima:/ } & \text { 'harmonized' } \\ \text { /k'ilt'u:/ } & \text { 'tree' } & \text { /Pila:lça/ } & \text { 'attitide' } \\ \text { /k'ulk'ullu:/ } & \text { 'neat' } & \text { /Pilka:n/ } & \text { 'teeth' }\end{array}$




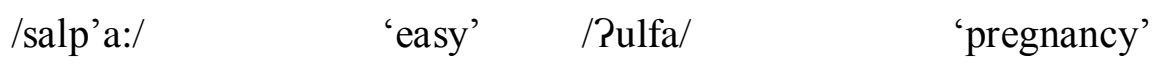

\section{$\mathrm{C}_{2} \mathrm{~S}$ of $\mathrm{C}_{1}$ Lateral sound in Oromo}

It is imperative to stress that the liquids (lateral and trill sounds) were seen to be the most widely occurring sounds in making the first member $\mathrm{CC}$ in Oromo. The second members are chiefly stops followed by ejectives. In case of sonority index, the sounds were assigned the lowest (1) considering ejectives as an obstruent while the lateral (being a liquid sound) were given higher sonority index (4). The distance between the first and the second member is three. Fricatives, nasal, and affricate sounds as well make the second member. The distances between these sounds and the lateral are relatively low (one for nasal, two for the fricatives). Note that an affricates are sounds placed between stops and fricatives (Juliette, 1995).

(4)

$\begin{array}{llll}\text { Instance Recorded } & \text { Gloss } & \text { Instance Recorded } & \text { Gloss } \\ \text { /torba/ } & \text { 'seven' } & \text { /harPa/ } & \text { 'today' } \\ \text { /farda/ } & \text { 'horse' } & \text { /marsa:/ } & \text { 'round' } \\ \text { /marga/ } & \text { 'grass' } & \text { /harma/ } & \text { 'breast' } \\ \text { /hark'o:ta/ } & \text { 'yoke' } & \text { /dubarti:/ } & \text { 'woman' } \\ \text { /harka/ } & \text { 'hand' } & \text { /k'urt'ummi:/ } & \text { 'fish' } \\ \text { /Purji:/ } & \text { 'star' } & \text { /k'arji:/ } & \text { 'money' } \\ \text { /borç'u:/ } & \text { 'shaking' } & \text { /murna/ } & \text { 'group' } \\ \text { /kurfa:yina/ } & \text { 'grouping' } & & \end{array}$

$\mathrm{C}_{2} \mathrm{~S}$ of $\mathrm{C}_{1}$ flap sound in Oromo

The other liquid sound is [r], which is the mostly prevalent first member in Oromo CCs as equal as the lateral sound. Forty percent of the consonants following the sound are 
stops. However, fricatives and ejectives can as well make part in the membership. Similar patterns manifest in their sonority differences with both sonorant consonants.

Examples (5) and (6) are giving you an idea about the instances recorded by using nasals as a first member. The language uses only two nasal sounds (the alveolar and the labial) in the anticipated position.

(5)

$\begin{array}{llll}\text { Instance Recorded } & \text { Gloss } & \text { Instance Recorded } & \text { Gloss } \\ \text { /hinda:k'k'o:/ } & \text { 'hen' } & \text { /k'e:nsa/ } & \text { 'nail' } \\ \text { /le:nç'a/ } & \text { 'lion' } & \text { /sa:nk'a:/ } & \text { 'door' } \\ \text { /danfa/ } & \text { 'sweat' } & \text { /Ramanti:/ } & \text { 'faith' } \\ \text { /sanga:/ } & \text { 'ox' } & \text { /konkola:ta:/ } & \text { 'car' } \\ \text { /le:nji:/3 } & \text { 'training' } & & \end{array}$

$\mathrm{C}_{2} \mathrm{~S}$ of $\mathrm{C}_{1}$ alveolar sound

As can be seen from example, the alveolar nasal (sonorous) coalesces with nine different phonemes with a dissimilar sonority. Most of these sounds are stops (four phonemes), fricatives (three phonemes) while the remaining phonemes are fricative and ejectives.

(6)

$\begin{array}{ll}\text { Instance Recorded } & \text { Gloss } \\ \text { /bo:mbi:/ } & \text { 'beetle' } \\ \text { /gamna/ } & \text { 'wise' } \\ \text { /da:msa/ } & \text { 'message' } \\ \text { /rom?e/ } & \text { 'he fluttered } \\ \text { /wa:mte/ } & \text { 'she called' } \\ \mathrm{C}_{2} \text { s of } \mathrm{C}_{1} \text { Labial /alveolar Nasal in Oromo }\end{array}$

\footnotetext{
${ }^{3}$ This is a phonemic way of expression, but phonetically the alveolar nasal often gets palatalized by undertaking a phonological processes termed as palatalization.
} 
The example shows that the labial nasal making a coda of a syllable in Oromo may combine chiefly with a stop consonant and sometimes with an alveolar fricative or nasal consonant. In this case the highly sonorous first member sound coalesces with the least sonorous sounds.

Example (7) is a case wherein a fricative /f/ and a glide /j/ make clusters. The sounds are categorized as obstruent and sonorant, respectively. Both sounds make a cluster with another obstruent (stop sounds). For the obstruent-obstruent CC the sonority difference is more or less nil while for the sonorant-obsruent $\mathrm{CCs}$ the difference is three (considering (Juliette, 1995) sonority index).

$\begin{array}{ll}\text { Instance Recorded } & \text { Gloss } \\ \text { /tofta:/ } & \text { 'technique' } \\ \text { [Pofwalla:lu:] } & \text { 'fainting' } \\ \text { /baaj?e:/ } & \text { 'many' } \\ \mathrm{C}_{2} \text { S of } \mathrm{C}_{1} \text { Fricatives and glide in Oromo }\end{array}$

In general, most $\mathrm{Cx}$ sounds in Oromo are sonorants such as $/ \mathrm{r}, 1, \mathrm{n}, \mathrm{m}, \mathrm{j} /$, but there are some obstruent Cxs too. The obstruent first members are stops and fricatives. Other sounds such as affricates, ejectives, and an implosive do not make CCs being a first member. But they can be the second member with either a sonorant or an obstruent sound.

\section{Discussion}

Languages' sounds constitute both consonants and vowels that have distinct patterns of arrangement depending on the phonotactics of the language. Similarly, Oromo has its own arrangement of sounds. As Wako (1981) stated, consonants singly take the word-initial and final position in the language. Yet, clusters of more than two consonants in the word medial position do not exist in the language. Consequently, there is no possibility of the cluster for 
consonants in an onset or coda position. In general, individual sounds and CCs of Oromo have their own distinctive distributions. The finding of the study was distinctly discussed in this section.

\subsection{The Distributions of Oromo Phonemes}

Wako (1981) asserted that from the stop consonants /p'/ does not occur word-initially which I disagree with for the existence of words like /p'a:p'alo:/ or /p'a:p'ali:/ 'a type of cranberry bean' and /p'erepp'eramu:/ 'to be scared' in the dialect. The other sounds categorized as stops can begin a word. Furthermore, from the fricatives, Wako (1981) claimed that /s/ does not word finally occur, although words like /gamas/ 'over there' or /Pakkas/ 'this way' are part of the dialect confirming the existence of occurrence.

Likewise, Habte (2003) stated that /č/ hardly exist in a word-initial position. In fact, it seems difficult to find an actual word of Oromo that begins with the sound, but there are words like /çe:/ 'an expression used to drive donkey'. Besides, there is a proper name /çu:çęe:/, which is mostly a females' nickname. Consequently, I argue that the sound may occur in word-initial position. That means even if their distribution is infrequent the sounds may appear in the specified position of a word. /sade:t/ 'eight' and / Pafur/ 'four' or /Peger/ 'a little while' are presumably some of the only words to finally possess /t/ and /r/ sounds, respectively. All the fricative sounds may come about word-initially or medially apart from the glottal fricative /h/, which is restricted to initial position only (Wako, 1981; Abera, 1988). In fact, word medially the sound serves sometimes as a free variant of the glottal stop. For instance, /na?e/ 'he's startled' can be surfaced as [nahe] alternating the glottal stop freely with the glottal fricative.

Majority of the words in Oromo end in vowel sounds although some consonant sounds such as /m, n, r, s, f/ more frequently occur word finally than other consonants (Habte, 2003). With the exception of these sounds, all the non-loan consonant segments, except /c, w, 
?, d/, may occasionally occur word finally in idiophone expressions (Dejene, 2010). From the affricates, no sound takes the word-final position; but all the nasals excepting the palatal nasal sound (which does not occur word finally) can take word-initial, medial, and final positions.

\subsection{Consonant Clusters}

As was indicated in the former studies, cluster of consonants is not permissible both word-initially and finally. All vowels both short and long do occur only in word medial and final positions (Habte, 2003; Degeneh, 2015; Tariku, 2019). That means there is no word that begins with a vowel while in clusters the maximum number of consonants allowed word medially is only two (Hawine, 2007). The finding of this study revealed a similar result with these prior works of Habte (2003) and Hawine (2007). Accordingly, the consonants make parts of different syllables in the syllabification of the language.

So, the language's phonotactics dictates the number of the consonants in a cluster. In English up to three consonants can make a cluster in a word initial and final position which Oromo does not allow $\mathrm{CC}$ in a word initial position. Even in the medial position the language do not allow more than two consonants to coalesce. In this case the consonants never make a coda or an onset with two sounds for each syllable node. So, in all cases where CCs exist in Oromo, the first member makes the coda of a syllable, while the next goes to the onset of a subsequent syllable. From this perspective, the language resembles with Amharic in that it does not allow more than two consonants in both word medial and final. Medially, Amharic also shares the sounds for two of the syllable nodes. Nonetheless, since the language possesses word final CCs, coda of an Amharic can have two consonants unlike Oromo.

In Oromo, a vowel would be inserted to limit the sequence into two consonants if a sequence of more than two consonants were likely to appear (Degeneh, 2015). Similarly, in 
one of the Omotic languages known as Dawro ${ }^{4}$ (spelt otherwise as Dauro or Dawuro) a cluster of consonants is allowed merely word medially, but disallowed either word initially or word finally (Tariku, 2010). However, in languages like English, consonant cluster can occur in all these three positions consisting of more than two consonants. In this case the syllable shape of the languages possesses a large number of consonants. For instance CCCVCCC type of clustering in English words like 'strengths' (Dawson \& Phelan, 2016) as opposed to Oromo, Dawro, and Amharic, the Ethiopian languages from different language families. Unlike the Dawro and Oromo, consonants can be in a cluster in both positions in Amharic, word medial and final positions, but not initially.

\section{Conclusion}

Here, a case of phoneme distribution and member types of CCs have been presented. CCs are rarely studied in Oromo (if any) and were difficult to know the exact number and type of clusters in the language. Normally, $\mathrm{CC}$ is permissible only in word medial position and the consonants are part of different syllables. The happenings of the consonants in the medial position as clusters itself have some restrictions as in every language of the world; merely some sounds can make clusters in Oromo. This dissimilarity in making CCs can be indicated in terms of sonority, which is assumed to be an auditory factor. So, a major concern here is to examine the status of sonorants in the phonological system of Oromo.

As for the sonority status of the consonants, Oromo has Sonorant-Obstruent, Obstruent-Obstruent, Obstruent-Sonorant and Sonorant-Sonorant clusters. From all the combinations majority of the language's CCs follow the Sonorant-Obstruent pattern that consists of nasal-liquid, nasal-fricative, nasal-ejective, liquid-stop, liquid-fricative, liquidejective, and glide-stop clusters. The rare CC in the language is apparently the SonorantSonorant cluster with first member nasal and liquid sounds coalesced with the nasal second

\footnotetext{
${ }^{4}$ It is part of the northern Ometo subgroup of the Benoyem subfamily.
} 
member. The other rare cluster type in the language is the Obstruent-Sonorant type built from a fricative $\mathrm{C} 1$ and a glide $\mathrm{C} 2$. Some of the remaining $\mathrm{CC}$ s of Oromo are obstruent sounds. These sounds can be in the order of stop-stop, stop-affricate, stop-fricative, and fricative-stop.

With great emphasis on the CCs of the language, it was pointed out that the happenings of the consonants in the medial position as clusters itself have some restrictions; and merely some sounds can make clusters. The language accordingly lets a small variety of word medial consonant clusters, while it is impossible elsewhere. Consequently, onset or coda of a syllable lacks cluster(s) attributable to impermissibility of more than two consonants in its formation of word medial clusters. Examining the status of sonorants in the varieties of the CCs first and second members, it has been pointed out that SonorantObstruent, Obstruent-Obstruent, Obstruent-Sonorant, and Sonorant-Sonorant clusters. From these varieties the type with sonorant first member is the dominant cluster type in the language. 


\section{References}

Abera, N. (1988). Long Vowels in Oromo. Addis Ababa: Unpublished MA Thesis: Addis Ababa University.

Abraham, T. N., Huang, D., \& Liu, X. (2014). Challenges of Diacritical Marker or Hudhaa Character in Tokenization of Oromo Text. Journal of Software, 9 (7), 1818-1826.

Dawson, H. C., \& Phelan, M. (Eds.). (2016). Language Files: Materials for an Introduction to Language and Linguistics (Twelfth Edition ed.). Columbus: The Ohio State University Press.

Degeneh, B. T. (2015). The Development of Oromo Writing System. Doctor of Philosophy $(\mathrm{PhD})$ thesis, University of Kent.

Dejene, G. (2019, March). An Acoustic Analysis of Fricatives Produced by Typically Developing Child and Adult Speakers of Oromo. Addis Ababa, Addis Abba University, Ethiopia: Unpublished PhD Dissertation: Addis Ababa University.

Dejene, G. (2010). Kamisee Oromo Phonology. Addis Ababa: Unpublished M.A. Thesis: Addis Ababa University.

Fasold, R., \& Connor-Linton, J. (Eds.). (2006). An Introduction to Language and Linguistics. Cambridge: Cambridge University Press.

Feda, N. (2015). Classification of Oromo Dialects: A Computational Approach. International Journal of Computational Linguistics (IJCL) , 6 (1), 1-10.

Fikadu, B. K. (2014). Dissimilation in Oromo Phonology. International Journal of Innovative research and Development (IJIRD) , 3 (13), 187-196.

Habte, B. (2003). Analysis of Tone in Oromo. Addis Ababa: Unpublished M.A. thesis: Addis Ababa University.

Hawine, A. (2007, July). The Structure of Nominal Clauses in Afan Oromo: A minimalist Approach. Addis Ababa: Unpublished MA Thesis: Addis Ababa University. 
Juliette, B. (1995). The syllable in phonological theory. In J. A. Goldsmith (Ed.), The handbook of phonological theory (pp. 206-44). Cambridge, MA: Blackwell.

Katamba, F. (1989). An introduction to phonology (Learning about Language Series). London and New York: Longman.

Kebede, H. J. (1994). Baate (Wello) Oromo Phonology: Palatalization of Alveo-dental Consonants and Related Issues. Addis Ababa: Unpublished MA thesis: Addis Ababa University.

Kebede, H. (2005). The Varieties of Oromo. (G. A. Demeke, Ed.) Ethiopian Languages Research Center Working papers , 134-149.

Lloret, M.-R. (1997). Oromo Phonology. In A. S. Kaye (Ed.), Phonologies of Asia and Africa (Including the Caucasus) (pp. 493-519). Winona Lake, Indiana: Eisenbrauns.

Mekuria, B. (1995). Onesimos Nasib's Pioneering Contributions to Oromo Writing. Nordic Journal of African Studies , 4 (1), 36-59.

Parker, S. G. (2002, May). Quantifying the Sonority Hierarchy. Unpublished PhD Dissertation . University of Massachusetts Amherst.

Rauch, T. D. (2003, October 19). Phonological Development in Child Language. University of Osnabrück, Germany.

Syrika, A., Nicolaidis, K., Edwards, J., \& Beckman, M. E. (2011). Acquisition of initial /s/stop and stop-/s/ sequences in Greek . Lang Speech, 361-386.

Tariku, N. (2010). A Description of Dauro Phonology: Some Aspects. Saarbrücken: VDM Verlag: Dr. Müller GmbH \& Co. KG.

Tariku, N. (2019, July). Acquisition of Oromo Phonology by Typically Growing Children. Addis Ababa, Ethiopia: Unpblished PhD Dissertation: Addis Ababa University.

Temesgen, N. (1993). Word Formation in Oromo. Addis Ababa: Unpublished MA Thesis: Addis Ababa University. 
Wako, T. (1981). The Phonology of Mecha Oromo. Addis Ababa: Unpublished MA Thesis: Addis Ababa University.

Yavas, M. (2013). Acquisition of \#sC clusters: universal grammar vs. language-specific grammar. Letras de Hoje , 48 (3), 355-361. 
Appendix A: Consonant sounds

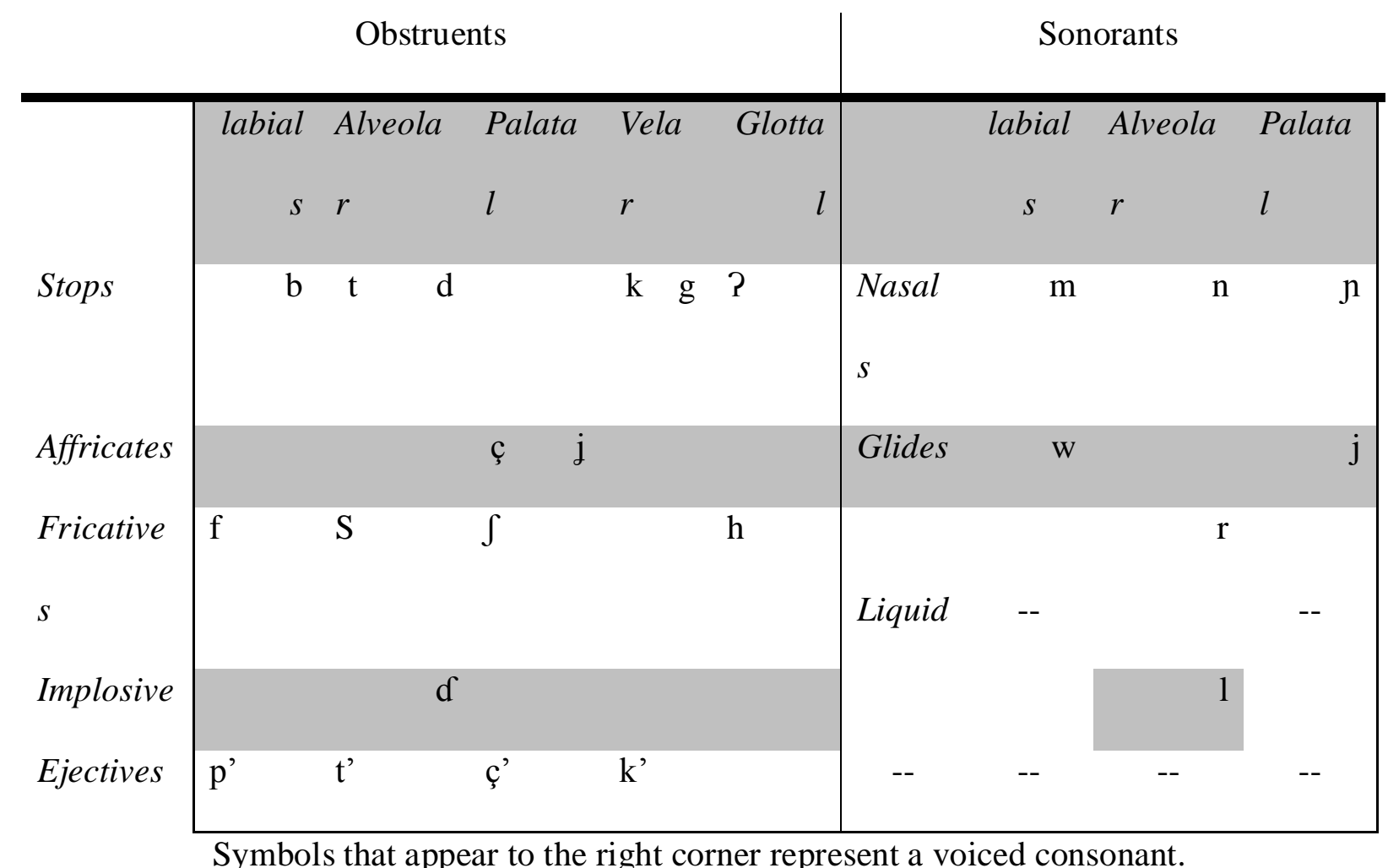

Appendix B: Vowel phonemes of Oromo

FRONT CENTRAL BACK

\begin{tabular}{c|ccc}
\hline Close & i & -- & u \\
Mid & e & -- & o \\
Open & & a &
\end{tabular}

Adapted from (Lloret, 1997) 